\title{
Охлаждаемые фотоприемные устройства ИК-диапазона на кадмий-ртуть-теллуре: состояние и перспективы развития
}

\author{
Н. Кульчицкий, д. т. н. ${ }^{1}$, А. Наумов ${ }^{2}$, В. Старцев ${ }^{3}$
}

УДК 621.315 .592 | ВАК 05.27 .06

\begin{abstract}
Состоянию и перспективам развития рынка неохлаждаемых тепловых фотоприемных устройств была посвящена статья "Рынок неохлаждаемых микроболометров для ИК-камер: тенденции и перспективы", опубликованная в нашем журнале в 2019 году (ЭЛЕКТРОНИКА: Наука, Технология, Бизнес, 2019, № 1 (00182)). Настоящий обзор посвящен анализу состояния и перспектив развития рынка охлаждаемых ИК фотоприемных устройств на кадмий-ртуть-теллуре.
\end{abstract}

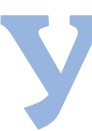

стройства с использованием тепловизоров позволяют осуществлять наблюдение в условияхплохой видимости, обнаруживать скрытые объекты, вести целеуказание. Они используются в системах технического зрения, для обеспечения безопасности авиа-и судовождения, контроля и охраны любых объектов. МчС применяет такие устройства при спасательных работах во время ликвидации пожаров, для определения наиболее опасных участков с высокой температурой [1].

По "до-пандемическому» прогнозу фирм Maxtech International и IndustryARC analysis (США) и сегодняшним оценкам авторов, общий рынок ИК-систем (гражданских и военных), составив 10,5 млрд долл. в 2017 году, в 2023 году достигнет почти 18 млрд долл. При этом рынок фотоприемных устройств для тепловизионных систем, составляющий 20-25\% от общей величины, может меняться по разным сценариям, как показано на рис. 1.

Если говорить о перспективах рынка ИК-систем в связи с сегодняшней пандемической ситуацией, то весьма вероятно, что эпидемиологическая

Российский технологический универсИтет (РТУ-МИРЭА), профессор. МГУ им. М. В. Ломоносова. Государственный научный центр РФ, АО "НПО "ОРИОН", Москва, n.kulchitsky@gmail.com AО "ОКБ "Астрон", Лыткарино, МО, старший научный сотрудник. АО «ОКБ "Астрон», Лыткарино, МО, Главный конструктор. угроза надолго займет в общественном сознании такое же место, какое после терактов в Нью-Йорке в 2001 году заняла террористическая угроза. Нельзя исключать появления в аэропортах биометрического контроля в дополнение к существующим протоколам авиационной безопасности, новых протоколов прохождения пунктов перехода границы и других применений. Это вызовет рост рынка Ик-систем [2].

В данной статье будут рассматриваться только некоторые свойства и характеристики наиболее широко применяемых в настоящее время охлаждаемых тепловых ИК-детекторов на полупроводниковом соединении кадмий-ртуть-теллур, а также возможные перспективы развития рынка.

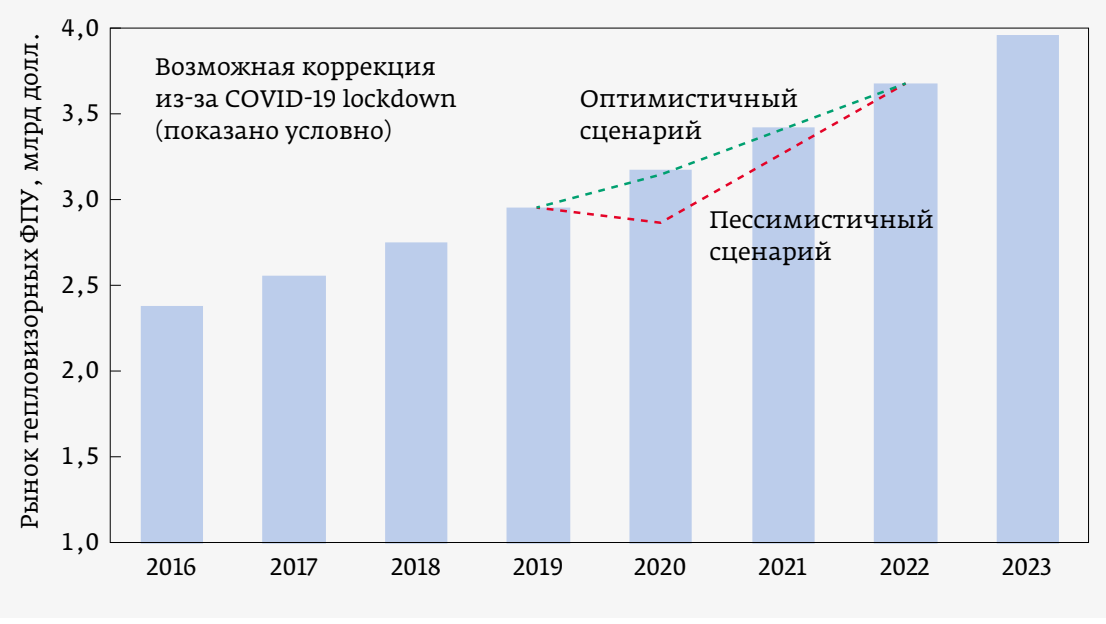

Рис. 1. Прогноз рынка ФПУ до 2023 года по разным сценариям. Источник: IndustryARC analysis и оценка авторов 


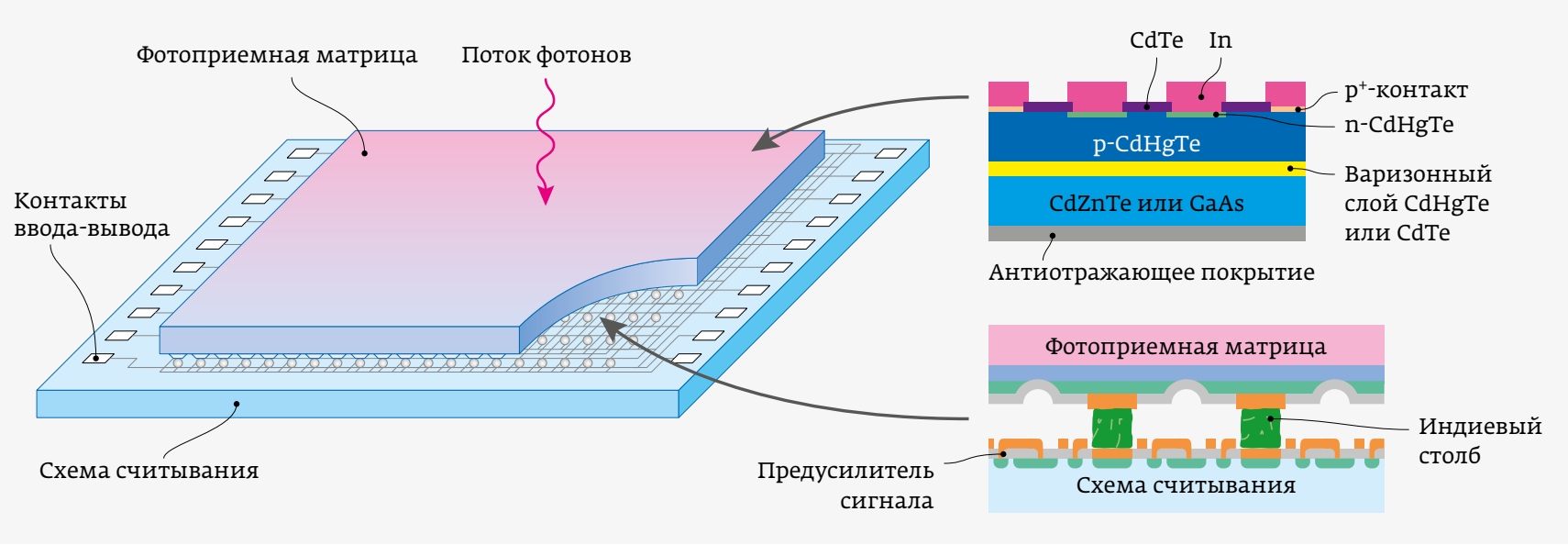

Рис. 2. Гибридизация МФПУ со считывающей схемой и схема пикселя

\section{КОНСТРУКЦИЯ СОВРЕМЕННЫХ ИК-СИСТЕМ И ДЕТЕКТОРОВ}

Инфракрасные камеры воссоздают образ теплого объекта по сигналам от первичных преобразователей - датчиков теплового излучения. Инфракрасная энергия от объектов сцены фокусируется посредством оптики на ИК-детектор, информация от него передается на электронику для обработки изображения, которое транслируется на стандартный видеоэкран. Современные датчики включают подложку, на которой размещен массив детекторов в фокальной плоскости focal plane array (FPA) - множество детектирующих элементов, представляющих собой пиксели. Подложка также включает интегральную схему, обычно называемую Read Out Integrated Circuit (ROIC), которая электрически соединяется с детектирующими элементами.

Интеграция таких схем (рис. 2) с разными типами детекторов позволила создавать матричные ИК-матрицы ФПУ (МФПУ), которые могут насчитывать до 10 ИК-детекторов, что соответствует числу чувствительных рецепторов в глазе человека $\left(-2 \cdot 10^{8}\right)$. В настоящее время на повестке дня стоит разработка инфракрасных МФПУ второго и третьего поколений. Ко второму поколению относятся односпектральные МФПУ смотрящего типа с числом элементов до 106 (мегапиксель). Третье поколение МФПУ характеризуется расширенными функциональными возможностями, реализующими многоспектральный прием оптического излучения, работу при повышенных температурах и другие применения. К третьему поколению относятся также МФПУ мегапиксельных форматов с уменьшенным шагом элементов.

\section{МФПУ НА КРТ}

Для ИК-детекторов спектральных областей 3-5 и 8-14 мкм (средневолновые ИК и длинноволновые ИК), как правило, требуется криогенное охлаждение (вплоть до температур 80-150 К), чтобы уменьшить скорость тепловой генерации носителей заряда. Типичная конструкция современного фотоприемного узла показана на рис. 3. Гибридный фотоприемный узел, включающий матрицу фоточувствительных элементов, состыкованную с кремниевой интегральной схемой считывания, смонтирован в вакуумный корпус МФПУ. Охлаждение МФПУ обеспечивается
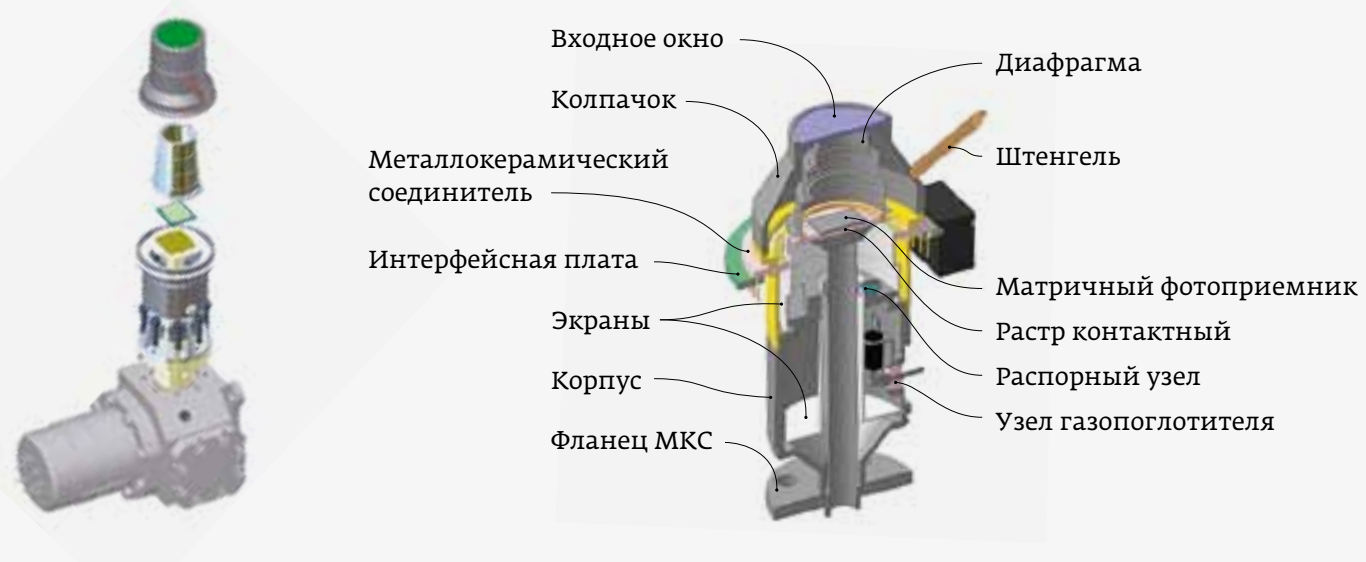

Рис. 3.

Конструкция модуля с охлаждаемым МФПУ 
микрокриогенной системой охлаждения (МКС), работающей по циклу Стирлинга.

\section{ОСНОВНЫЕ ПОЛУПРОВОДНИКОВЫЕ ФОТОЧУВСТВИТЕЛЬНЫЕ МАТЕРИАЛЫ}

Основой МФПУ являются полупроводниковые фоточувствительные материалы. В последнее время круг этих исходных материалов для инфракрасной фотоэлектроники обозначился достаточно ясно. Доминирующими для охлаждаемых МФПУ остаются соединения кадмийртуть-теллур (HgCdTe, КPT) на спектральные диапазоны 1-2,5, 3-5, 8-14 мкм и антимонид индия (InSb) на диапазон 3-5 мкм (рис. 4). Значительное расширение областей применения МФПУ коротковолнового ИК-диапазона спектра (0,9-1,7 мкм) привело к развитию тройного полупроводникового соединения индий-галлий-мышьяк (InGaAs), появлению охлаждаемых МФПУ на основе сверхрешеток (InAs / GaSb Type II SL) и квантовых ям (QW, QD) [3, 4].

\section{КРТ - ОСНОВНОЙ МАТЕРИАЛ СОВРЕМЕННОЙ ИНФРАКРАСНОЙ ФОТОНИКИ}

С середины 1980-х годов КРТ утвердился в мире как основной материал Ик- фотоэлектроники, оставив позади (вместе c InSb) по объему продаж другие полупроводниковые фоточувствительные материалы. Две первые работы, посвященные исследованию системы CdTe-HgTе, были опубликованы в Англии Лоусоном (1959 г.) и в СССР-А.Д. Шнейдером из Львовского педагогического института (1960 г.). Из результатов работ следовало, что оба соединения обладают бесконечной растворимостью по отношению друг к другу и образуют непрерывный ряд твердых растворов с плавно меняющейся шириной запрещенной зоны. Меняя состав (x) твердого раствора $\mathrm{Cd}_{x} \mathrm{Hg}_{1-x}$ Те в пределах 0,2-0,5, можно было получить материал, пригодный для детектирования ИК-излучения во всех трех диапазонах ("окнах" прозрачности земной атмосферы) - 1,5-2,5; 3-5 и 8-14 мкм.

Исследования были активно продолжены в Англии, Франции и США. Опыт войны во Вьетнаме убедил руководство этих стран в необходимости развития работ по тепловидению и, прежде всего, в так называемой дальней области ИК-спектра (8-14 мкм), где лежит максимум спектральной излучательной способности замаскированной техники, военных объектов, живой силы противника.

Первая работа по технологии КРТ в СССР была начата в НИИ прикладной физики (г. Москва) в 1969 году под руководством профессора В.И. Стафеева, научного руководителя и главного конструктора направления КРТ в НПО “Орион». Вскоре начались и работы по созданию приемников из выращенного материала. Технология получения КРТ носит сложный многоступенчатый характер и включает тонкую очистку исходных Cd, Hg и Те, синтез соединений HgTe и CdTe, получение поликристаллов
$48 \%$ InSb
$40 \% \quad \mathrm{HgCdTe}$
$6 \%$ InCaAs
2\% QWIP
4\% Прочие

\section{Рис. 4. Доли различных материалов в продажах ИК-систем}

и монокристаллов CdHgTе. Кадмий, ртуть и теллур имеют довольно высокие упругости пара над расплавом, что может вызывать значительные отклонения от стехиометрии кристалла $\mathrm{Cd}_{x} \mathrm{Hg}_{1-x}$ Те. Обычно сразу после синтеза монокристаллы содержали большое количество структурных дефектов, связанных как с простыми вакансиями ртути, так и со сложными вакансиями, сопровождающимися смещением соседних атомов теллура. Это кардинально отличает КРТ от большинства полупроводников - здесь электрически активными являются не только примесные атомы, но и собственные точечные дефекты кристаллической решетки. Поэтому для получения низкой концентрации электронов в П-КРТ необходимо подвергать образцы материала длительному высокотемпературному отжигу в насыщенных парах ртути или ртути с кадмием при точном поддержании режимов в течение нескольких сотен часов. Все это делало материал чрезвычайно дорогим. Работа была начата с конструирования и изготовления оборудования для выращивания монокристаллов. За основу был принят метод Бриджмена, ранее успешно использовавшийся при изготовлении других полупроводников. При этом было ясно, что для получения сравнительно узкого диапазона составов $(x=0,18-0,21)$, необходимого для приемников на область спектра 8-14 мкм, требуется иметь температуру в зоне расплава порядка $800^{\circ} \mathrm{C}$ (давление при этой температуре более 12 атм). Отклонение режима роста в этих условиях всего на $1{ }^{\circ} \mathrm{C}$ вызывало заметное изменение состава кристалла $\mathrm{Cd}_{x} \mathrm{Hg}_{1-x}$ Те. Все режимы необходимо было реализовать в кварцевых ампулах в условиях высокой чистоты. Такого оборудования в СССР не было, и первые ростовые установки были сконструированы и изготовлены в НИИ прикладной физики собственными силами в 1969 году.

В 1969 году были синтезированы и первые слитки монокристаллического материала КРТ, из которых удавалось вырезать небольшие пластинки нужного состава. Позже уникальное оборудование для выращивания КРТ было разработано конструкторами института Гиредмет (Москва) и изготовлено на опытном производстве. 
Большой вклад в освоение технологии КРТ внесли институты Гиредмет и НИИ прикладной физики, а также работа коллектива Завода чистых металлов в Светловодске (директор - А. М.Тузовский).

К середине 1980-х годов КРТ утвердился в мире как основной материал ИК-фотоэлектроники, оставив позади по объему продаж все другие полупроводниковые фоточувствительные материалы. За последние 40 лет технология получения КРТ интенсивно развивалась, что позволило перейти от изготовления объемных монокристаллов КРТ относительно небольшого диаметра (менее 10 мм) до эпитаксиальных слоев КРТ на подложках большого диаметра (до 150 мм), изготовленных из другого, но подходящего по физическим параметрам материала. В настоящее время все структуры КРТ получают методом эпитаксии на подложке, структурно, химически, оптически и механически согласованной с КРТ [3-6].

Эпитаксиальные структуры (ЭС) КРТ получают методами жидкофазной эпитаксии (ЖФЭ), методом осаждения из газовой фазы из паров металлоорганических соединений (MOCVD) и методом молекулярно-лучевой эпитаксии (МЛЭ).

Основные преимущества метода ЖФЭ: относительно низкая стоимость и высокая производительность оборудования, автоматическая доочистка поверхности на начальном этапе роста, дополнительная очистка от примесей в процессе роста и однородность состава по площади.

Эпитаксиальные структуры на основе $\mathrm{Cd}_{x} \mathrm{Hg}_{1-x} \mathrm{Te}$, полученные MOCVD-методом, по своим характеристикам не уступают слоям, полученным по другим технологиям. K достоинствам MOCVD-метода получения эпитаксиальных слоев $\mathrm{Cd}_{x} \mathrm{Hg}_{1-x}$ Те относят его гибкость и относительно высокую производительность.

Метод МЛЭ имеет свои преимущества перед другими методами выращивания слоев КРТ. К преимуществам МлЭ относятся: низкая температура роста; наиболее чистые условия выращивания и соответственно низкий уровень фонового легирования; возможность получения многослойных объектов.

Этот подход особенно перспективен для получения структур большого диаметра - применение гибридных или так называемых альтернативных подложек, которые представляют собой многослойные структуры, состоящие из пластин объемного кристалла, закрытых буферными слоями с согласованной решеткой. Правда, до настоящего времени не найдено подложки, которая удовлетворяла бы одновременно всем требованиям [4].

\section{КАДМИЙ-ЦИНК-ТЕЛЛУР - ОСНОВНОЙ ПОДЛОЖЕЧНЫЙ МАТЕРИАЛ ДЛЯ КРТ}

Подложки из монокристаллического cdTе и тройных соединений на его основе, в первую очередь cdZnTe (кадмий-цинк-теллур или КЦТ), физически и химически согласованы с CdHgTе и позволяют выращивать эпитаксиальные слои с параметрами, соответствующими качеству объемных кристаллов [4, 5].

Исторически первой коммерческой технологией выращивания монокристаллов КЦТ является метод Бриджмена, который впервые появился в Харьковском НИИ монокристаллов (Украина) и затем был передан в компанию eVProducts (США). В настоящее время данным методом получают бо́льшую часть производимого КЦТ в мире. Однако используемое высокое давление обусловливает структурное несовершенство, возникающее в процессе роста кристалла. Появляющиеся дефекты развиваются и кристалл имеет невысокое структурное совершенство. Получаемая заготовка ("буля») часто обладает блочной структурой, то есть состоит из блоков монокристаллов (рис. 5). Впоследствии такой кристалл "разбирается» на монокристаллические блоки. Подобным методом кристаллы выращивают также Saint-Gobain Crystals (США), Eurorad (Франция).

Другой технологией является тот же метод Бриджмена в модификации с низким давлением. Таким способом удается получать кристаллы лучшего качества, чем при использовании высокого давления. Данную технологию отработали компании Orbotech (Imarad) (Израиль), YinneTech (США), Letti (Франция).

Компании 5NPlus (Канада), Redlen (Канада) выращивают КЦТ методом зонной плавки, ИФТТ РАН (Черноголовка) - методами HPVZM (high-pressure vertical zone melting). Kromek (Великобритания) и НИИМВ (Зеленоград) получают монокристаллический материал методом выращивания из паровой фазы.

В Советском Союзе первые ЭС КРТ были получены в 1970-1973 годах по методу изотермической эпитаксии [4]. В Гиредмете для выращивания ЭС КРТ был выбран метод жидкофазной эпитаксии на подложке из КЦТ. Разработанный под руководством В. М. Лакеенкова, научного руководителя направления и заведующего лабораторией КРТ в AO «Гиредмет», метод выращивания монокристаллов

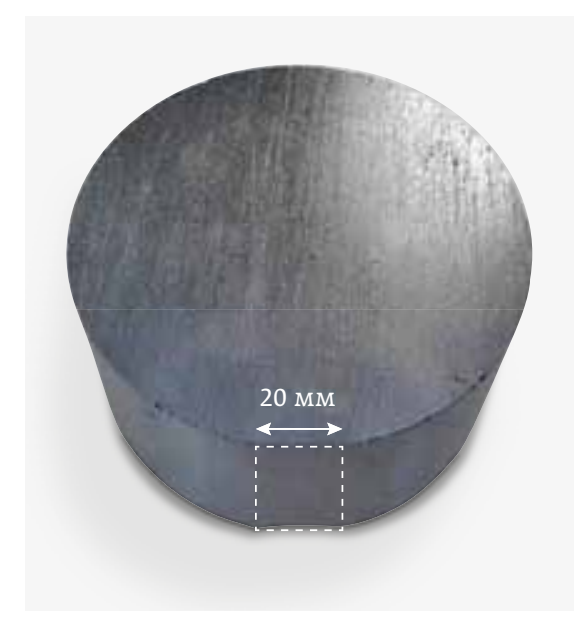

Рис. 5. Современный кристалл КЦт диаметром $100 \mathrm{MM}$, длиной $60 \mathrm{MM}$ (Университет Гренобля) [6] 


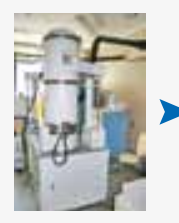

Выращивание кристаллов cdZnTe

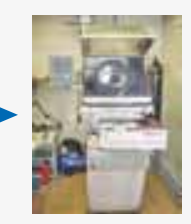

Ориентированная резка кристаллов

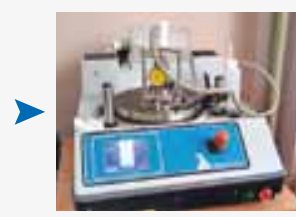

Изготовление подложек

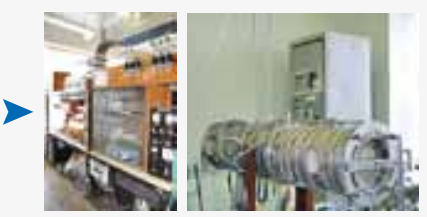

Жидкофазная эпитаксия HgCdTe

при использовании альтернативных подложек может ухудшаться из-за образования промежуточных химических соединений на гетерограницах и интенсивного дефектообразования на них. При сопряжении кристаллов, относящихся к разным структурным типам (CdHgTе и Si), возможно образование специфичных дефектов. Все эти проблемы приводят к сложности достижения высокого структурного совершенства гетероэпитаксиальных структур кРТ и его электрофизических параметров, необходимых

Рис. 6. Технологическая цепочка получения эпитаксиальных слоев КРТ / КЦТ в Гиредмете

cdZnTe основан на модернизированной технологии изготовления кристаллов КРТ методом вертикальной или горизонтальной кристаллизации расплава при температурах 1120-1130 C с последующим охлаждением при скорости не более $10^{\circ} \mathrm{C} / 4$. Эта технология обеспечила получение монокристаллических, прозрачных в ИК-области подложек с диаметром более 30 мм, плотностью дислокаций не выше (5-8) ·10 см$^{-2}$ при отсутствии малоугловых границ и включений второй фазы. Этими работами были заложены основы промышленного выпуска эпитаксиального материала для фотодиодов в России (рис. 6). В настоящее время выпуск эпитаксиальных слоев ведется в Гиредмете (руководитель - И. А. Денисов) [1, 3, 5].

\section{"АЛЬТЕРНАТИВНЫЕ" ПОДЛОЖЕЧНЫЕ МАТЕРИАЛЫ ДЛЯ СЛОЕВ КРТ}

Подложки большой площади из CdZnTe остаются дорогим изделием с плохо воспроизводимыми характеристиками. Малый размер, проблемы чистоты, преципитация теллура, неоднородность состава по площади и высокая цена (60-500 долл. за 1 см²) делают невозможным использование таких подложек в массовом производстве и при создании широкоформатных матриц фотодетекторов. В связи с этим повсеместно разрабатываются технологии создания гетероструктур CdHgTе на альтернативных подложках, таких как Si, GaAs, Ge. Объемные полупроводниковые материалы Ge, Si, GaAs являются высококачественными, сравнительно дешевыми кристаллами. Цена за один квадратный сантиметр кремниевой подложки составляет менее 1 долл., тот же показатель для КЦТ составляет 250 долл. Ge, Si и GaAs прозрачны в ИК-области и могут быть использованы при создании приборов для любого спектрального диапазона. В качестве буферных слоев наносятся пленки ZnTe и CdTе суммарной толщиной несколько микрон.

При гетероэпитаксии CdHgTе на подложках из GaAs и Si возникают проблемы, обусловленные различиями в параметрах решеток сопрягаемых материалов и различной природой химической связи. Структурное совершенство для изготовления ИК-фотоприемников с предельными характеристиками.

Среди подложечных материалов для КРТ за рубежом выбор остановился на КЦТ, кремнии и германии. В США (Raytheon Vision Systems, Rockwell Scientific Company, Teledyne Imaging Sensors, DRS) в основном используют подложки из КЦТ и кремния. Lynred (Франция) остановилась на подложках из германия. Несмотря на некоторое удорожание по сравнению с кремнием, за счет меньшего рассогласования параметров решеток получено наилучшее (после КЦТ) качество МлЭ КРТ. В России наиболее отработанным методом промышленного получения ЭС КРТ остается ЖФЭ (Гиредмет). Так»е МЛЭ ЭС КРТ реализована на подложках GaAs и Si в ИФП СО РАН. Там разработана технология и изготовлено оборудование для решения данной задачи.

\section{МАТРИЧНЫЕ ФОТОПРИЕМНЫЕ УСТРОЙСТВА НА КРТ}

Растущие требования по увеличению дальности видения, уменьшению массогабаритных характеристик аппаратуры, отказу от механической развертки стимулировали в конце 1970-х годов поиск новых типов фотоприемных устройств, к которым стали относить двумерные (матричные) структуры формата $\mathrm{N} \times \mathrm{N}, \mathrm{M} \times \mathrm{N}$ и другие. Coвременные МФПУ могут насчитывать до $10^{8}$ ИК-детекторов. По сложности технологии такие приемники во много раз превосходили все созданные к началу этих разработок. Требовалось решить проблему изготовления приемников, содержащих десятки тысяч фоточувствительных элементов.

В настоящее время матричные устройства на основе фотодиодов из КРТ представляют собой сложные фотоэлектронные информационные комплексы, в состав которых, помимо матрицы фотодиодов и охлаждаемой микроэлектроники считывания фотосигналов, входят микрокриогенная система охлаждения и специальные микропроцессорные цифровые устройства, обеспечивающие на выходе последовательность тепловизионных 
Таблица 1. Матричные ФПУ на основе КРТ различных производителей

\begin{tabular}{|c|c|c|c|c|c|c|c|}
\hline марка & Mars LW & Scorpio LW & Hawk LW & Harier LW & $\begin{array}{c}\text { АСТРОН- } \\
640 \mathrm{KPT} 15 A 810\end{array}$ & - & HiPIR-640L \\
\hline $\begin{array}{l}\text { Фирма, } \\
\text { страна }\end{array}$ & \multicolumn{2}{|c|}{$\begin{array}{c}\text { Lynred, } \\
\text { Франция }\end{array}$} & \multicolumn{2}{|c|}{$\begin{array}{c}\text { Finmeccanica, } \\
\text { Англия }\end{array}$} & $\begin{array}{c}\text { ОКБ Астрон / } \\
\text { ИФП СО РАН, } \\
\text { Россия }\end{array}$ & $\begin{array}{c}\text { НПО Орион, } \\
\text { Россия }\end{array}$ & $\begin{array}{c}\text { AIM Infrarot- } \\
\text { Module GmbH } \\
\text { Германия }\end{array}$ \\
\hline Формат & $320 \times 256$ & $640 \times 512$ & $640 \times 512$ & $640 \times 512$ & $640 \times 512$ & $640 \times 480$ & $640 \times 512$ \\
\hline Шаг, мкм & 30 & 15 & 16 & 24 & 15 & 28 & 15 \\
\hline Технология & \multicolumn{2}{|c|}{$\mathrm{HgCdTe} / \mathrm{Ge}$} & \multicolumn{2}{|c|}{ HgCdTe / КЦТ } & $\mathrm{HgCdTe} / \mathrm{Si}$ & HgCdTe/ КЦТ & HgCdTe / КЦТ \\
\hline $\mathrm{T}_{\mathrm{pa} 6}, \mathrm{~K}$ & 80 & 80 & 80 & 80 & 70 & $\leq 80$ & 67 \\
\hline
\end{tabular}

сигналов в стандартном телевизионном формате. МФПУ, представленные в сравнительной табл. 1, выпускаются серийно ведущими мировыми производителями и в России и наиболее широко представлены на мировом рынке. Основной формат - 640 × 512 пикселей, осуществляется переход на $1280 \times 1024$ пикселей.

\section{СИТУАЦИЯ В РОССИИ}

В России проблема обеспечения разработок и производства в области ИК-фотоэлектроники отечественными фоточувствительными материалами стоит достаточно остро. К настоящему времени удалось разработать технологии и создать производственные участки по выпуску некоторых фоточувствительных материалов, в том числе эпитаксиальных структур КРТ, а также полупроводниковых подложек КЦТ (АО «Гиредмет»).

Разработкой фотоприемных устройств различного назначения в России занимаются ряд предприятий, сосредоточенных в АО «Швабе» и АО «Росэлектроника», в Российской академии наук, а также частные предприятия. Основными поставщиками тепловизионных ФПу и МФПУ являются АО «НПО "Орион» и АО «МЗ Сапфир", входящие в АО «Швабе», а также частное предприятие АО "ОКБ "Астрон". АО "НПО "Орион" разрабатывает и ведет производство охлаждаемых и неохлаждаемых фотоприемников, материаловедческая база предприятия ориентирована на молекулярно-лучевую эпитаксию. AO «M3 «Сапфир" производит охлаждаемые и неохлаждаемые ФПУ на основе Si, Ge, InSb, CdHgTe. Институт физики полупроводников Сибирского отделения РАН развивает ФПУ на основе CdHgTe, InAs, микроболометров и квантовых ям. АО "ОКБ «Астрон» (г. Лыткарино МО) разрабатывает и производит тепловизионные приборы гражданского назначения на основе неохлаждаемых МФПу собственного производства, а также охлаждаемых МФПу (на основе CdHgTe/Si совместно с ИФП СО РАН) с использованием микрохолодильной системы «Астрон-МКС500».
Таким образом, в настоящее время в России разработаны МФПУ второго поколения, а также крупноформатные и смотрящие ИК ФПУ. Достигнутые результаты близки по своим показателям к мировому уровню [8].

\section{ТЕНДЕНЦИИ РАЗВИТИЯ МФПУ НА КРТ}

Уменьшение шага и повышение формата является всеобщим трендом практически для всех мировых разработчиков и производителей МФПУ на КРТ. Фирма Leonardo (Великобритания) уже достигла шага 8 мкм для матриц мегапиксельного формата средневолнового ИК-диапазона, а фирма Lynred (Франция) к 2021 году планирует достичь шага 5-7 мкм для таких матриц и совместно с научным центром CEA LETI (Франция) проводит интенсивные работы в этом направлении.

Формат МФПУ 640 × 512 элементов при шаге 15 мкм является в настоящее время основным форматом и, по-видимому, по соотношению "цена - качество" на ближайшие 5-10 лет он таковым и останется. Ведущими фирмами-разработчиками МФПУ в качестве коммерчески доступного достигнут мегапиксельный формат $1280 \times 1024$ элементов. В настоящее время цены на такие матрицы достаточно высоки и не позволяют разработчикам аппаратуры осуществить массовый переход на этот формат. Однако уже к 2025 году такой переход произойдет

В последние 10-15 лет активно развивается направление "высокотемпературных" МФПУ, в которых существенно повышена относительно жидкого азота рабочая температура охлаждения фоточувствительного слоя, при этом температурная чувствительность и качество инфракрасного изображения не снижается. К настоящему времени достигнут достаточно высокий уровень развития в средневолновом спектральном ИК-диапазоне (табл. 2). Повышение рабочей температуры охлаждения МФПУ позволяет применить МКС с существенно сниженными весогабаритными и мощностными показателями и, соответственно, менее дорогие. Дополнительно достигается 
Таблица 2. "Высокотемпературные" МФПУ на КРТ

\begin{tabular}{|c|c|c|c|c|c|}
\hline марка & Epsilon & Leo-LP-MW & Daphnis -HD & Hot HAWK & Super HAWK \\
\hline Фирма, страна & \multicolumn{3}{|c|}{ Lynred, Франция } & \multicolumn{2}{|c|}{ Leonardo, Англия } \\
\hline Формат & $384 \times 288$ & $640 \times 512$ & $1280 \times 1024$ & $640 \times 512$ & $1280 \times 1024$ \\
\hline Шаг, мкм & 15 & 15 & 10 & 16 & 8 \\
\hline Технология & HgCdTe & HgCdTe & HgCdTe & HgCdTe & HgCdTe \\
\hline $\mathrm{T}_{\mathrm{pa}}, \mathrm{K}$ & 110 & 120 & $\leq 120$ & 110 & 80 \\
\hline Мощность, Вт & 2,5 & 4,4 & 6,5 & 6 & 6 \\
\hline Macca, г & 280 & 380 & 550 & 350 & 350 \\
\hline
\end{tabular}

повышение ресурса и время автономной работы прибора в портативной аппаратуре при ограниченной емкости источника питания. Заметно снижается и время выхода на рабочий режим. При повышении температуры охлаждения с 80 до 150 К у МФПУ формата 640 × 480 элементов фирмы Leonardo потребляемая в стационарном режиме мощность уменьшается в два раза, а время выхода на режим - почти в два раза.

Интенсивное развитие направления "высокотемпературных» МФПУ за рубежом и отнесение этого направления к наиболее важным обусловлено перспективами их использования в носимых тепловизионных приборах, портативных приборах наблюдения и разведки, БПЛА и другой аппаратуре, где важны малая потребляемая мощность, вес и габариты.

Повышение температуры охлаждения фоточувствительного слоя в МФПУ напрямую связано с разработкой новых фоточувствительных эпитаксиальных структур, обеспечивающих при повышенных температурах охлаждения низкие темновые токи и, как следствие, малые собственные шумы. Гетероэпитаксиальная инженерия методами молекулярно-лучевой эпитаксии (МЛэ) и эпитаксии из металлоорганических соединений позволяет формировать оптимизированные фоточувствительные структуры с запорными, буферными и барьерными слоями, в которых устраняются отдельные компоненты темновых токов. В результате существенно повышаются фотоэлектрические характеристики МФПУ.

Одна из основных технологий получения "высокотемпературных» МФПУ - на основе специализированных гетероструктур КРТ. Основным форматом здесь также является $640 \times 512$ элементов, а по числу элементов достигнут мегапиксельный формат (см. табл. 2).

Таким образом, за рубежом за последнее время произошло значительное продвижение в области инфракрасных матричных фотоприемных устройств и передовые образцы МФПУ становятся доступны потребителям все в большей степени [1, 7, 8]. $\because *$

Последнее десятилетие можно охарактеризовать как период стремительного развития технологий теллурида кадмия-ртути и приборов на его основе. Основа, заложенная в 1960-1980-х годах специалистами НИИ прикладной физики, Гиредмета, Сибирского НИИОС, Завода чистых металлов и многих других организаций, позволила решить крупную научно-техническую проблему по созданию элементной базы для нового поколения приборов тепловидения, теплопеленгации, лазерной локации и связи, высокосовершенных монокристаллов и эпитаксиальных слоев КРТ и инфракрасных матричных фотоприемных устройств на их основе. Несмотря на изобилие новых идей и методов регистрации ИК-излучения в диапазоне 8-14 и 3-5 мкм (квантовые ямы, сверхрешетки на основе широкозонных полупроводников и другие структуры), эти приборы вместе с фотоприемниками на основе InSb и микроболометрами вероятнее всего будут доминировать в оптикоэлектронном приборостроении ближайшего будущего.

Двух- и многоспектральные МФПУ активно разрабатываются практически всеми ведущими фирмами. Достигаемое при их применении повышение информативности и вероятности обнаружения и распознавания, а также компактность комплексированных оптико-электронныхсистем являются основными движущими силами развития этого направления. В следующем десятилетии двухспектральные МФПУ наряду с мегапиксельными и «высокотемпературными" станут основными коммерчески доступными изделиями ИК-фотоэлектроники. Для реализации двухспектральных МФПУ, чувствительных в диапазонах 3-5 и 8-12 мкм, применяют технологии на основе КРТ.

Мы считаем, что динамику развития МФПУ на основе КРТ можно оценить, как представлено на рис. 7.

В России нарастает отставание от ведущих зарубежных компаний в области разработки МФПУ и просто финансовых, пусть даже значительных, "вливаний» в существующие организационные структуры для его преодоления недостаточно. Задачи достижения паритета с мировым 
уровнем, а также создания научнотехнического и технологического заделов для развития МФПУ могут быть решены программно-целевым методом, предусматривающим проведение комплекса мероприятий технического, финансового и организационного характера в рамках механизма государственно-частного партнерства.

\section{ЛИТЕРАТУРА}

\section{1. Бурлаков И.Д., Пономарен-}

ко В.П. Современное состояние и тенденции развития фотоэлектроники // Материалы XXV Международной научно-технической конференции по фотоэлектронике и приборам ночного видения. М.: НПО Орион, 2018. С. 5

2. Старцев В.В., Наумов А. В. Состояние и перспективы развития охлаждаемых фотоприемных устройств на кадмий-ртутьтеллуре // Технологии защиты. 2019. № 6. С. 21-23.

3. Филачев А. М., Таубкин И. И., Тришенков М. А. Твердотельная фотоэлектроника. Фоторезисторы и фотоприемные устройства. - М.: Физматкнига, 2012. 368 с

4. Пономаренко В.П. Теллурид кадмия-ртути и новое поколение приборов инфракрасной фотоэлектроники // Успехи физических наук. 2003. Т. 173. № 6. С. 649-665

5. Rogalski. Next decade in infrared detectors // Proc SPIE10433. Electro-Optical and Infrared Systems: Technology and Applications XIV. 104330L (9 October 2017).

6. Bisotto S., Abergel J., Dupont B., Ferron A., Mailliart O., Nicolas J. A. $7.5 \mu \mathrm{m}$ and $5 \mu \mathrm{m}$ pitch IRFPA developments in MWIR at CEA-Leti // Proc. SPIEl1002. Infrared Technology and Applications XLV. 110021C (7 May 2019); DOI: $10.1117 / 12.2519330$

7. Сизов Ф.Ф.ИК-фотоэлектроника: фотонные или тепловые детекторы? Перспективы // Sensor Electronics and Microsystem Technologies. 2015. T. 12. № 1. C. $25-52$.

8. Самвелов А. В., Ясев С. Г., Москаленко А.С., Старцев В.В., Пахомов О.В. Микрокриогенная система Стирлинга с комбинированным регенератором и магнитокалорической ступенью охлаждения // Фотоника. 2019. Т. 13. № 5. С. 496-499. DOI: 10.22184 / FRos.2019.13.5.496.499.

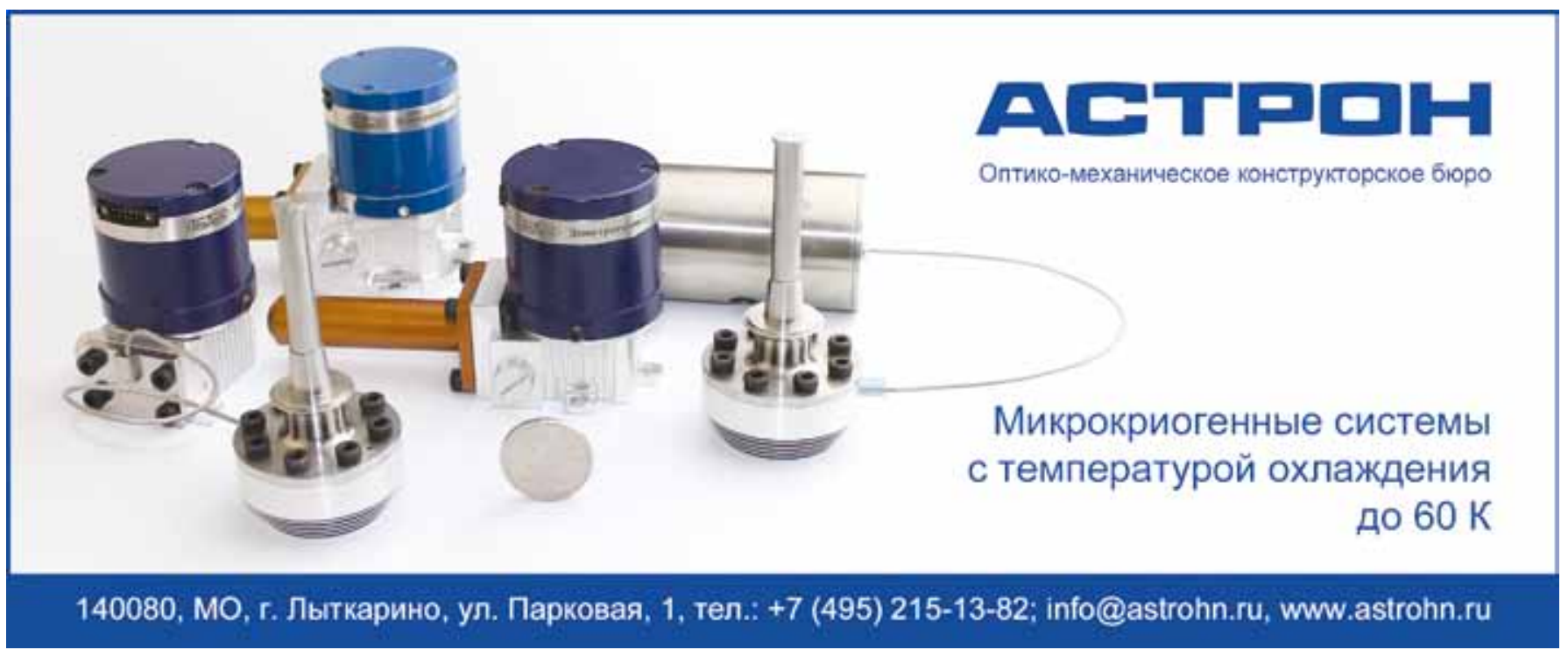




\section{ИМС категории качества «ВП» ПЗУ информационной емкостью 1 Мбит 1675РТ014}

Микросхема 1675РТ014 - ПЗУ, однократно электрически программируемая емкостью 1 Мбит с организацией накопителя $128 \mathrm{~K} \times 8$ бит. Микросхема предназначена для применения в высоконадежных высокопроизводительных вычислительных системах обработки информации и системах управления специального назначения с ограниченными энергетическими и весогабаритными характеристиками с номинальным напряжением $3,3 \mathrm{~B}$.

Микросхема изготавливается в металлокерамическом корпусе типа 4149.36-1 и функционирует при температуре от -60 до $+125^{\circ} \mathrm{C}$. Технические условия - AEHB. $431210.476-01$ TУ.

Таблица 1. Электрические параметры микросхем при приемке и поставке (при $U_{c c}=3,0 \div 3,6$ B)

\begin{tabular}{|c|c|c|c|c|}
\hline \multirow{2}{*}{$\begin{array}{c}\text { Наименование параметра, единица измерения, } \\
\text { режим измерения }\end{array}$} & \multirow{2}{*}{$\begin{array}{c}\text { Буквенное } \\
\text { обозначенме } \\
\text { параметра }\end{array}$} & \multicolumn{2}{|c|}{ Hopma napametpa } & \multirow{2}{*}{$\begin{array}{l}\text { Temnepar ypa } \\
\text { среды. 'C }\end{array}$} \\
\hline & & He merese & He 6 ones & \\
\hline $\begin{array}{l}\text { Выходное напряжение низкого уровня, В } \\
\text { при Іо }=2,0 \mathrm{MA}\end{array}$ & Uot & - & 0,4 & \multirow{11}{*}{$\begin{array}{l}25 \pm 10 \\
-60,125\end{array}$} \\
\hline $\begin{array}{l}\text { Выходное напряжение высокого уровня, В } \\
\text { при tом }=\mid-2 \text {. 이 мA }\end{array}$ & $\mathrm{UOH}$ & $U_{c c}-0.8$ & - & \\
\hline $\begin{array}{l}\text { Ток утечки низкого уровня на входе, мкA } \\
\text { при } U_{i L}=08\end{array}$ & late & - & $|-10|$ & \\
\hline $\begin{array}{l}\text { Ток утечки высокого уровня на входе, мка } \\
\text { при } U_{i н}=U_{c c}\end{array}$ & ILH & - & 10 & \\
\hline $\begin{array}{l}\text { Ток утечки низкого уровня на выходе, мкА } \\
\text { при } \cup o \iota=0 \text { В }\end{array}$ & lont & - & $|-20|$ & \\
\hline $\begin{array}{l}\text { Ток утечки высокого уровня на выходе, мка } \\
\text { при } \cup_{о н}=U_{c c}\end{array}$ & loLH & - & 20 & \\
\hline Ток потребления в режиме хранения, мкА & Iccs & - & 60 & \\
\hline $\begin{array}{l}\text { Динамический ток потребления, мА, } \\
\text { при } f=4 \text { МГц }\end{array}$ & loce & - & 40 & \\
\hline Время выбора, нс & $\operatorname{tes}$ & - & 120 & \\
\hline Время выборки разрешения выхода, нс & twoes & - & 60 & \\
\hline Козффициент программируемости & NPR & 0,6 & - & \\
\hline
\end{tabular}

Таблица 2. Предельно-допустимые злектрические режимы эксппуатации микросхем

\begin{tabular}{|c|c|c|c|}
\hline \multirow{3}{*}{$\begin{array}{c}\text { Наименование параметра режима, } \\
\text { единица измерения }\end{array}$} & \multirow{3}{*}{$\begin{array}{c}\text { Буквенное } \\
\text { обозначение } \\
\text { параметра }\end{array}$} & \multirow{2}{*}{\multicolumn{2}{|c|}{$\begin{array}{c}\text { Предепьно-допустимыи режким } \\
\text { Норма параметра }\end{array}$}} \\
\hline & & & \\
\hline & & He менее & He бonee \\
\hline Входное напряжение низкого уровня, В & $\mathrm{Uiti}_{\mathrm{i}}$ & 0 & $0,2 \times U_{C C}$ \\
\hline Входное напряжение высокого уровня, В & $U_{i H}$ & $0,8 \times$ Uee & Uec \\
\hline Входной ток низкого уровня, МКА & Ia. & - & $| \pm 10|$ \\
\hline Выходной ток высокого уровня, МА & $\mathrm{lOH}$ & - & $|-2,0|$ \\
\hline Выходной ток низкого уровня, МА & loL & - & 2,0 \\
\hline
\end{tabular}




\section{Мультиплексор записи}

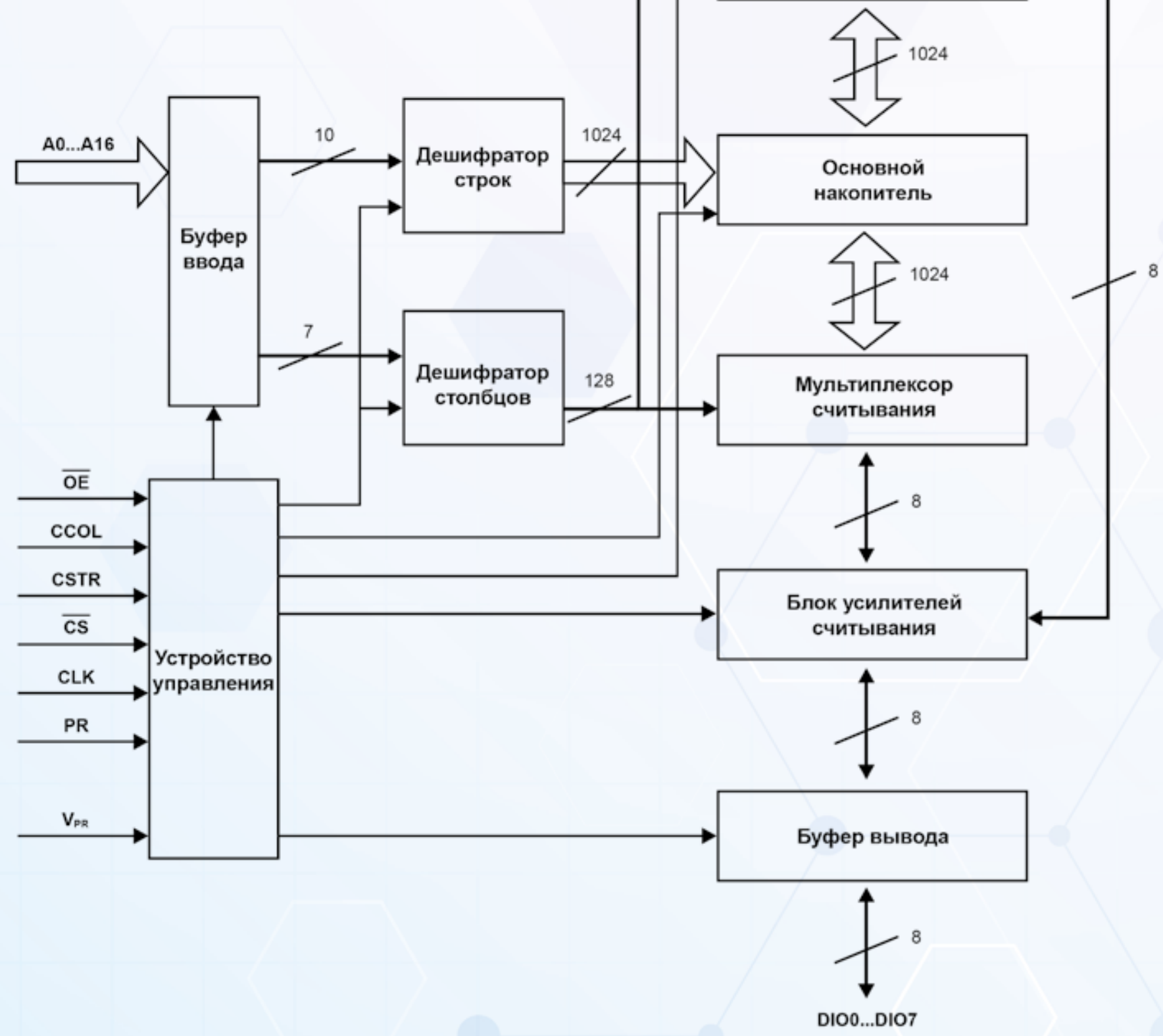

Таблица 3. Таблица истинности

\begin{tabular}{|c|c|c|c|c|c|c|c|}
\hline \multirow{2}{*}{ Режим работы } & \multicolumn{7}{|c|}{ Логические состояния на выводах } \\
\cline { 2 - 8 } & $\overline{\mathrm{CS}}$ & $\overline{\mathrm{OE}}$ & $\mathrm{PR}$ & $\mathrm{CLK}$ & $\mathrm{CSTR}$ & $\mathrm{CCOL}$ & $\mathrm{DIO0-DI07}$ \\
\hline Хранение & $\mathrm{H}$ & $\mathrm{X}$ & $\mathrm{L}$ & $\mathrm{L}$ & $\mathrm{L}$ & $\mathrm{L}$ & $\mathrm{Z}$ \\
\hline Считывание & $\mathrm{L}$ & $\mathrm{H}$ & $\mathrm{L}$ & $\mathrm{L}$ & $\mathrm{L}$ & $\mathrm{L}$ & $\mathrm{Z}^{*}$ \\
\hline
\end{tabular}

Микросхема 1675РТ014 стойкая к воздействию специальных факторов 7.И, 7.К и 7.С по ГОСТ РВ 20.39.414.2 с характеристиками 7.И1 - 4Ус; 7. И6 - 5Ус; 7.И7 $-6 \mathrm{Y}_{\mathrm{c}} ; 7 . \mathrm{C}_{1}-50 \times 5 \mathrm{У}_{\mathrm{c}} ; 7 . \mathrm{C}_{4}-10 \times 5 \mathrm{У}_{\mathrm{c}} ; 7 . \mathrm{K}_{1}-5 \times 2 \mathrm{~K} ; 7 . \mathrm{K}_{4}-5 \times 1 \mathrm{~K}, 7 . \mathrm{K}_{9}$

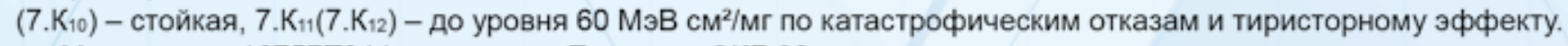

Микросхема 1675РТ014 включена в Перечень ЭКБ 02.

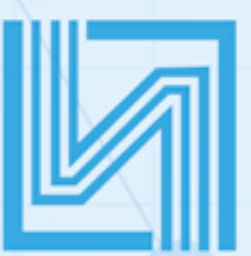

\section{ОАО «ИНТЕГРАЛ"}

Управляющая компания холдинга «ИНТЕГРАЛ» Республика Беларусь 